\title{
Influence of Type of Grinding Stone on Rail Grinding Efficiency
}

\author{
Yoshikazu KANEMATSU \\ Frictional Materials, \\ Materials Technology Division \\ Yukio SATOH
Frictional Materials, \\ Yukio SATOH
Frictional Materials,
}

\begin{abstract}
Rail grinding is a traditional part of maintenance employed to mitigate rail damage such as shelling and corrugation. In order to improve the efficiency of grinding operations in the field, new grinding stones were developed and evaluated in this study. The improvement in grinding capacity of the developed grinding stone compared with the current grinding stone was confirmed, as was its improved grinding performance due to its more moderate impact on rails from a metallographic point of view despite the improved grinding performance. Based on these results, it is expected that the developed grinding stone has the potential to be introduced to field grinding operations.
\end{abstract}

Keywords: rail grinding, grinding stone

\section{Introduction}

Rail grinding has been a traditional part of maintenance for a long time in order to mitigate rail damage such as shelling and corrugation, especially on Shinkansen lines [1]. Based on the positive results obtained for Shinkansen lines, rail grinding has also been introduced to conventional lines in recent years in Japan.

One of the issues which must be considered in rail grinding is the noise produced at the wheel/rail interface. The change in sound level and frequency produced by passing trains just after grinding is regarded as an increase in rolling noise in areas with a high population density [2]. As a countermeasure, to the grinding machine was operated at a different speed in the final pass from that of other passes to control the corrugation pitch produced by grinding which is a potential source of rolling noise. An increase in the speed of the grinding car may result however in a decrease of the total amount of material which can be ground, because at a higher speed, the length time spent by the grinding machine in each section is shorter. In order to maintain the grinding efficiency even under such conditions, it is therefore necessary to use a higher performance grinding stone. Performance has to be even higher for sections of line across urban areas due to the limited time available for such operations: usually only around midnight on such lines.

Though many investigations [3, 4] have been made in an attempt to find countermeasures to this problem, few studies have concentrated on obtaining high-performance grinding stones. This study therefore has developed and evaluated a new type of grinding stone. The properties of the developed grinding stone and its influence during grinding on the rail were also examined from the metallurgical point of view.

\section{Grinding tests}

A small type braking material test bench was modified to make a grinding test rig for evaluating the performance of the grinding stones in question. The bench was designed to evaluate samples of the grinding stone, in product form, with a rotational speed of up to $2500 \mathrm{rpm}$ and maximum axial load of $2000 \mathrm{~N}$. The test bench can be seen in Fig. 1.

The rail specimens were mounted on fixed holders and pressed against the grinding stone which rotated around a fixed axis at various rotating speeds and pressing loads for each of the evaluation tests. These tests revealed a clear difference between laboratory and grinding conditions in the field. The relative position of the rail specimen and grinding stone did not change on the test bench whereas the grinding stone during grinding operations in the field moves along the target rail.

The rail specimens were prepared out of the head of

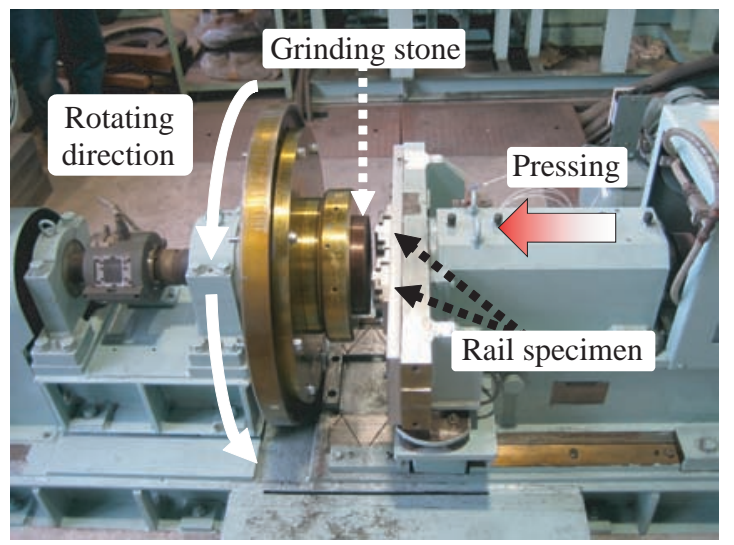

Fig. 1 Grinding stone test machin

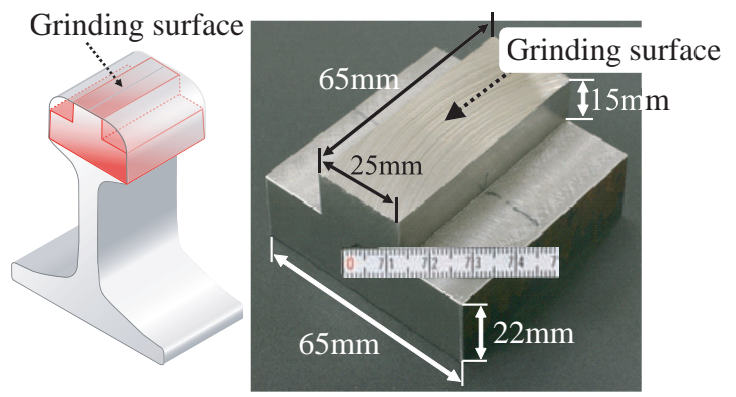

Fig. 2 Sampling position and shape of rail specimen 
$60 \mathrm{~kg}$ rails, as defined in JIS E 1101. Figure 2 shows the shape and size of a specimen.

\section{Machine test conditions}

\subsection{Determining the test conditions}

Reproducing conditions as close as possible to reality is important to evaluate the grinding stone performance: both in terms of the contact point between the grinding stone and the rail and relative movement between the grinding stone and the rail. However, due to rotation speed and axial load constraints on the test bench, this was not entirely possible.

In order to choose best alternative test conditions, it was assumed that test conditions would be favorable if the grinding chips produced in test conditions were similar in shape and size to those produced during field grinding operations. Following this idea, the grinding chips generated under various experimental conditions of rotating speed and pressing load were compared with chips collected from field grinding operations from rails in service. The test conditions which produced chips closest in shape and size to those produced under real conditions, were therefore selected.

\subsection{Chips obtained in field grinding operations}

Grinding chips were collected in the field during grinding operations on rails in service. The grinding operation was carried out with a SPENO RR16M6 grinding car equipped with 16 normal type grinding stones. Normally, water is sprayed throughout the grinding operation in order to prevent fire caused by flying sparks during the process. In this case however, water was not sprayed in the periods where grinding chips were collected to prevent the chips from rusting. The grinding chips were collected at several intervals from successive grind-

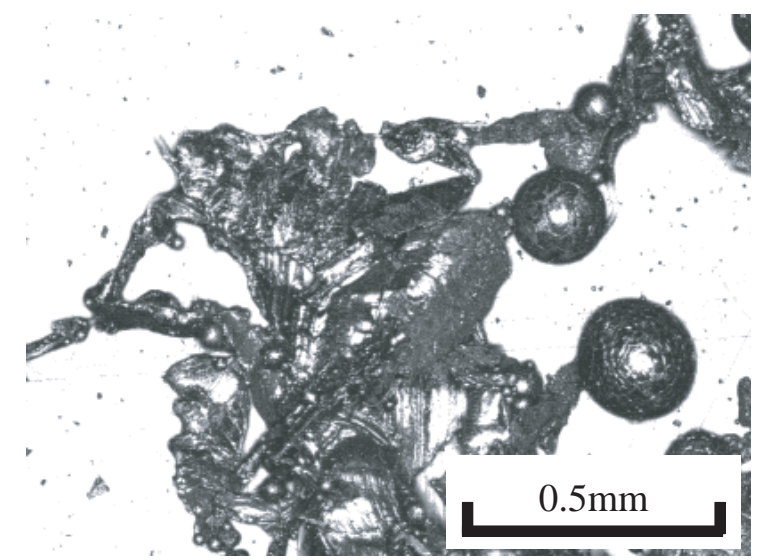

Fig. 3 Typical morphology of chips from field grinding

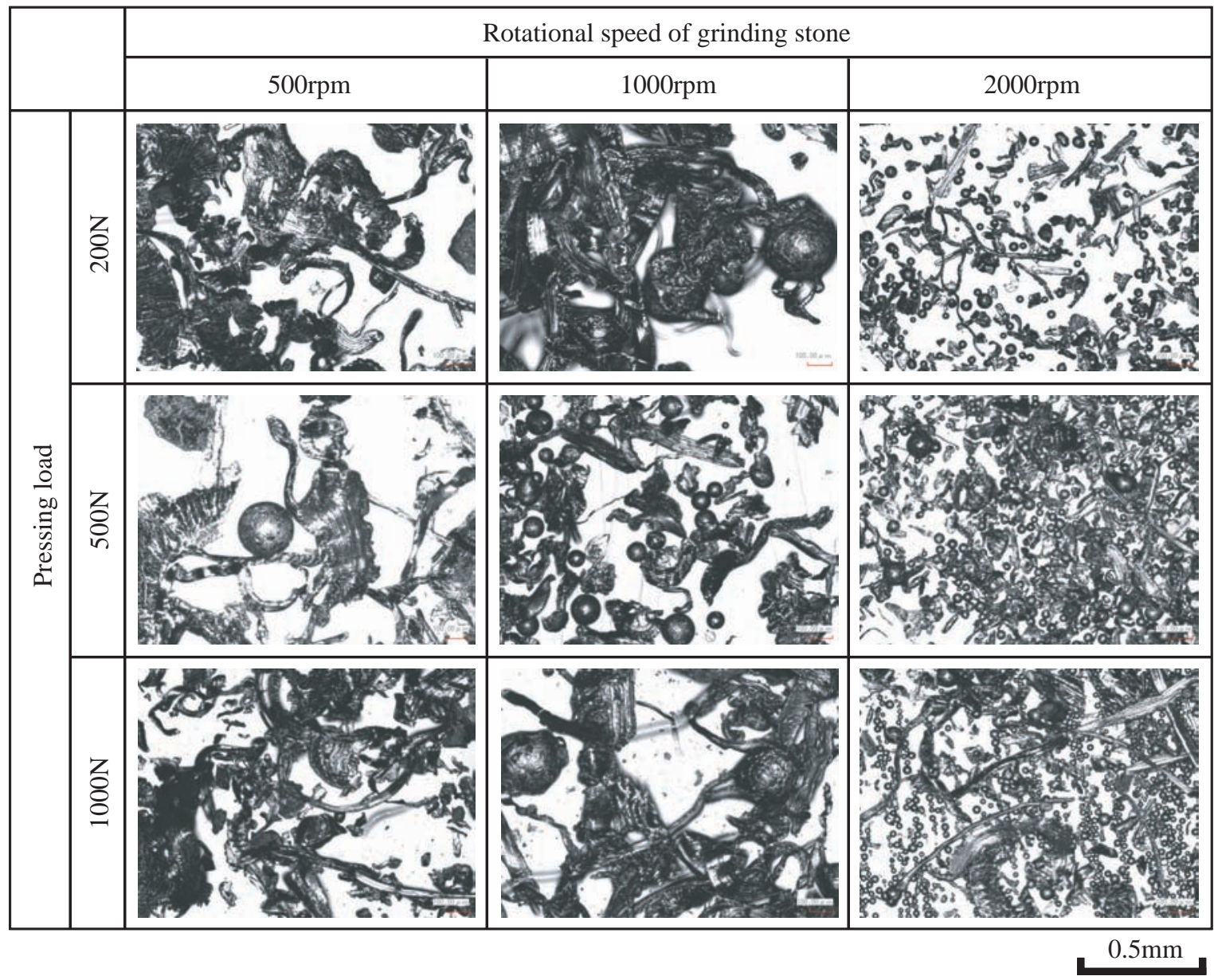

Fig. 4 Morphology of grinding chips collected during preliminary tests 
Table 1 Preliminary test conditions

\begin{tabular}{l|c}
\hline Rotational speed & $200,500,1000 \mathrm{rpm}$ \\
\hline Pressing load & $200,500,1000 \mathrm{~N}$ \\
\hline Grinding time & 4 sec/cycle \\
\hline Grinding interval & $60 \mathrm{sec}$ \\
\hline Number of cycles & 3 \\
\hline
\end{tabular}

ing passes from the running surface and base of the rail.

The morphology of the collected chips was observed by means of a laser microscope. Typical grinding chips magnified 200 times are shown in Fig. 3. The chips appear to be similar presenting a typical morphology as shown in Fig. 3 accompanied by small spheres probably generated during a molten phase, caused by high temperatures produced by grinding.

\subsection{Chips obtained in machine tests}

A series of preliminary machine tests was carried out under nine different conditional combinations, configured from rotating speeds of 500, 1000 and $2000 \mathrm{rpm}$ and pressing loads of 200,500 and $1000 \mathrm{~N}$ using the current grinding stone. The grinding chips were collected in a sampling tray during the test and examined as described below. The test conditions are summarized in Table 1.

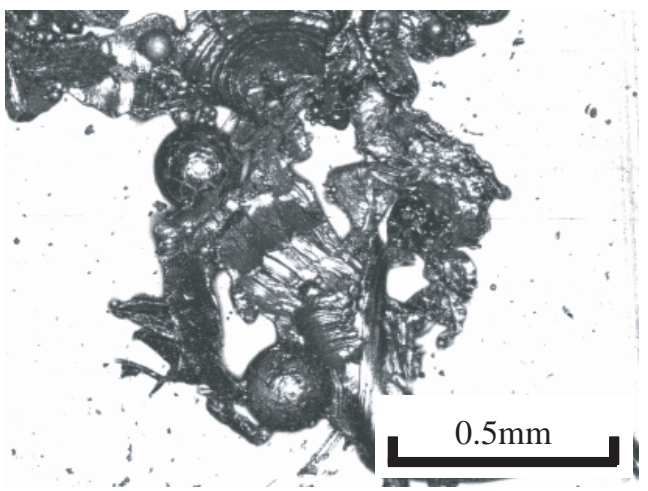

(a) Chips from the field grinding operations

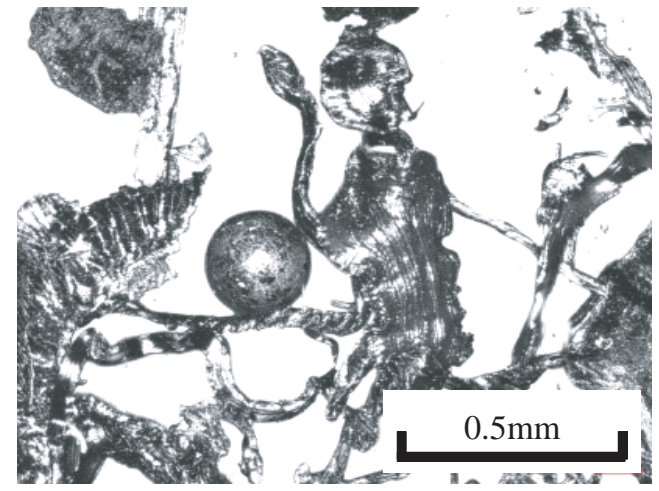

(b) Chips from preliminary machine tests

Fig. 5 Comparison of grinding chips
Morphology of the collected grinding chips was observed by means of a laser microscope with 200 times magnification. The appearance of the chips for each different set of experimental conditions is tabulated in Fig. 4. The typical morphologies of the grinding chips were ribbon, granular, and spherical. An increase in rotating speed gave rise to an increase in the ratio of spherical grains and finer grains in the grinding chips for all pressing load conditions. On the other hand, no obvious differences were observed in morphology when pressing load alone was increased at any fixed rotating speed.

\subsection{Determination of the test conditions}

Test conditions were determined so that the grinding chips collected in the machine test presented as similar a morphology as possible to the grinding chips collected during field grinding operations. Of the grinding chips collected in machine tests, the ones most similar to those collected in the field grinding operations are shown in Fig. 5 along side the chips collected in the field. Based on this comparison, the conditions deemed most suitable for reproducing conditions as close as possible to the field comprised a pressing load of $500 \mathrm{~N}$ and a rotating speed of $500 \mathrm{rpm}$.

\section{Machine tests on the grinding stones}

\subsection{Grinding stones for evaluation}

Figure 6 is a diagram of the basic structure of a grinding stone. The factors that define the characteristics of a grinding stone are the material and size of abrasive grain, the type of binding material and size and ratio of pores to the stone volume. Seven different types of grinding stones with varying configurations of these factors were prepared and provided for the machine tests. The prototype stones were all the same shape as current grinding stones used in field grinding operations. Table 2 shows the properties of the seven samples.

\subsection{The experiment}

On the basis of the aforementioned test conditions, machine tests were performed on each of the prototypes

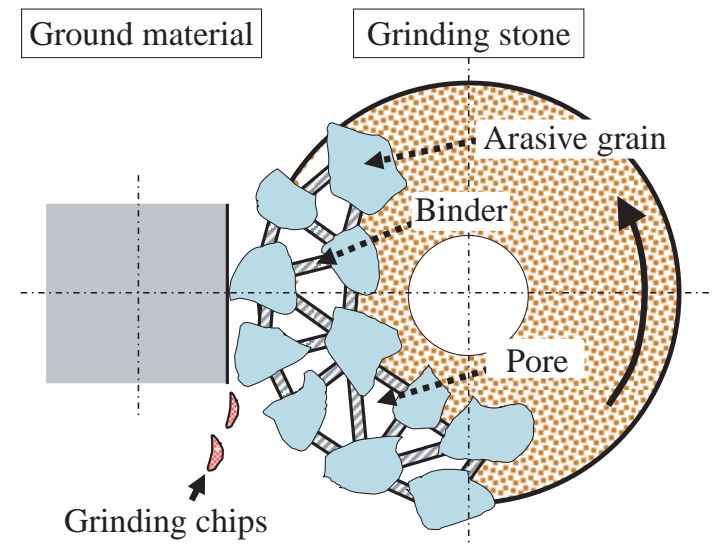

Fig. 6 Diagram of the basic structure of a grinding stone 
Table 2 Summary of prototype grinding stones

\begin{tabular}{c|l}
\hline Type & \multicolumn{1}{|c}{ Specification } \\
\hline \hline A & Comparable to the current stone \\
\hline B & Modified A with lower elasticity binding material \\
\hline C & Modified A with lower hardness abrasive grain \\
\hline D & Modified C with different abrasive grain material \\
\hline E & Modified D with harder hardness abrasive grain \\
\hline F & $\begin{array}{l}\text { Modified B with lower hardness abrasive grain, } \\
\text { smaller grain size }\end{array}$ \\
\hline G & Modified F with different abrasive grain material \\
\hline
\end{tabular}

Table 3 Conditions of machine test

\begin{tabular}{l|c}
\hline Rotational speed & $500 \mathrm{rpm}$ \\
\hline Pressing load & $500 \mathrm{~N}$ \\
\hline Grinding time & $6 \mathrm{sec} / \mathrm{cycle}$ \\
\hline Grinding interval & $60 \mathrm{sec}$ \\
\hline Number of cycles in a set & $10 \mathrm{cycle} / \mathrm{set}$ \\
\hline Number of sets & 10 \\
\hline Accumulated grinding time & $600 \mathrm{sec}$ \\
\hline
\end{tabular}

and the current grinding stone. The weight of rail specimen was measured before and after grinding tests in order to evaluate the amount of material removed. Table 3 summarises the experimental conditions.

An evaluation test on a grinding stone consisted of 10 sets of series of pressing the grinding stone to the rail specimen. A series consisted of 10 presses for 6 seconds at 60 second intervals. Between successive sets, the specimen was detached and attached again upside-down in order to prevent slipping between the grinding stone and the rail specimen which could occur since the relative position of the grinding stone and the rail specimen remained unchanged.

\subsection{Results}

Figure 7 gives the material loss through grinding in the machine tests. The prototype grinding stones demonstrated a higher grinding performance compared to the current grinding stone.

Among them, type D showed the highest performance while type E had the lowest. Type A was comparable to the current grinding stone. Type D uses a different type of abrasive material which was expected to improve grinding capability. Though type E consisted of the same abrasive material and binder as type $\mathrm{D}$, the hardness of the stone which was greater type D produced the different grinding performance.

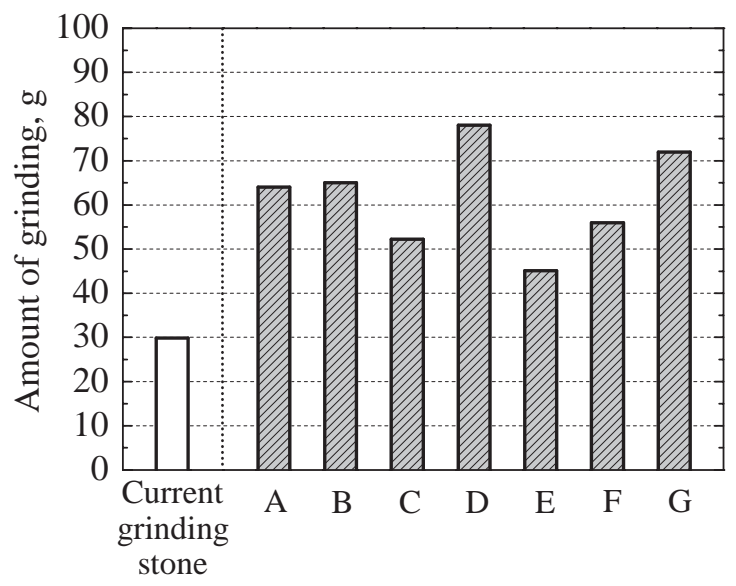

Fig. 7 Grinding performance of the prototype grinding stones

\section{Rail specimens after the machine tests}

Characterization of the surfaces of rail specimens ground by the type $\mathrm{D}$ prototype and the current grinding stone were carried out after machine test.

\subsection{Ground surface of the rail specimen}

Figure 8 shows the surface of the rail specimens after grinding in the machine tests. No bluing was detected as a result of the heat produced from grinding friction. After visual inspection, the roughness of the ground surface was measured by means of a surface roughness meter in the normal direction following concentric grinding marks. The surface roughness of the samples were evaluated and compared using the arithmetical mean roughness $R a$ against a sampling length of $15 \mathrm{~mm}$ as a measure. The $R a$ of the ground surface with the current grinding stone was $14.3 \mu \mathrm{m}$ while that with the type D grinding stone was $9.7 \mu \mathrm{m}$.

The comparison of the surface roughness showed that

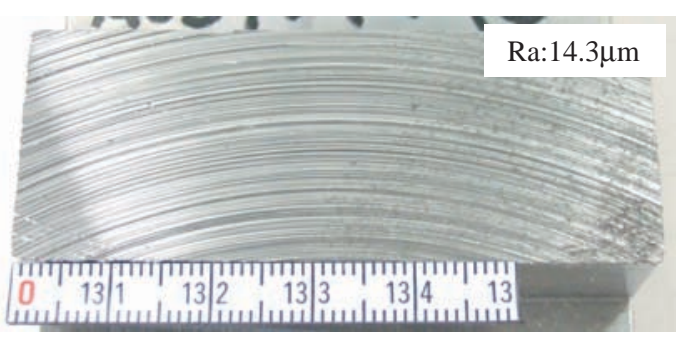

(a) Current grinding stone

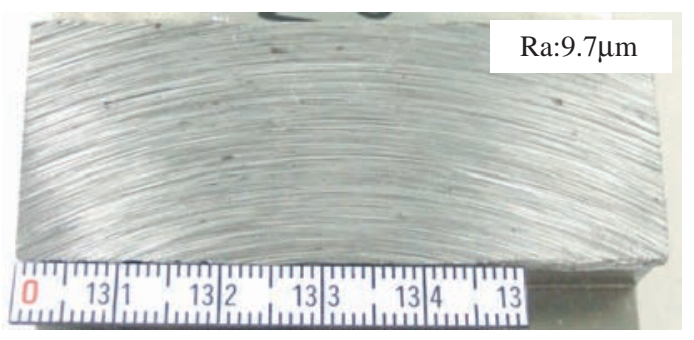

(b) Type D grinding stone

Fig. 8 Surface of the rail specimens after grinding 
the type $\mathrm{D}$ grinding stone could reduce roughness by about $30 \%$ compared to the current grinding stone. It showed that, despite its higher grinding capability, the type D grinding stone ground rails just as smoothly as if not more than the current grinding stone.

\subsection{Metallographic observations}

Metallographic observations were carried out in order to verify any influence of the grinding on the properties of the material in rail specimen tread surface. The position of the section for optical microscopic observation was as shown in Fig. 9.

The section for metallographic observation was finished with a standard process such as etching of a mirror polished surface with Nital (3\% nitric acid with $97 \%$ alcohol).

Figure 10 shows the metallographic structures of the rail specimens ground with the current and the type $D$ grinding stones. A white etching layer was observed on the rail specimens' tread surface after grinding by both the current and type D grinding stones. It was presumed that the white etching layer was formed by heat gener-

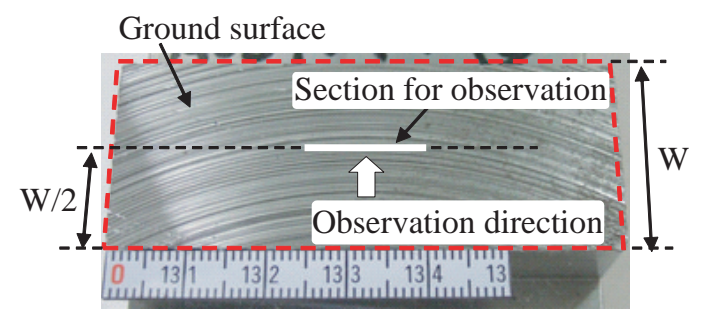

Fig. 9 Position and direction for optical microscopic observation

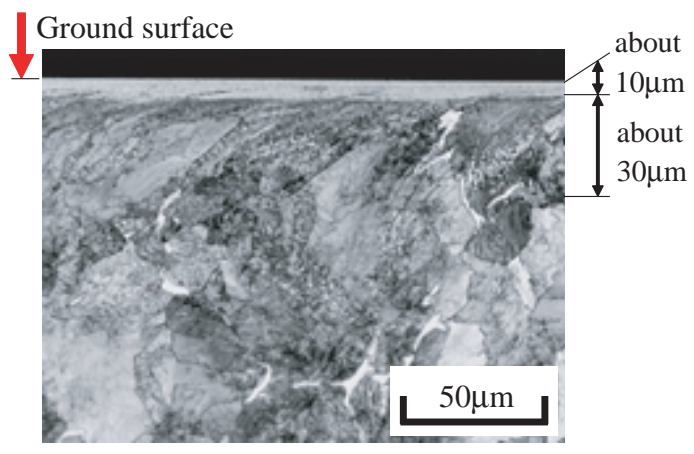

(a) Current grinding stone

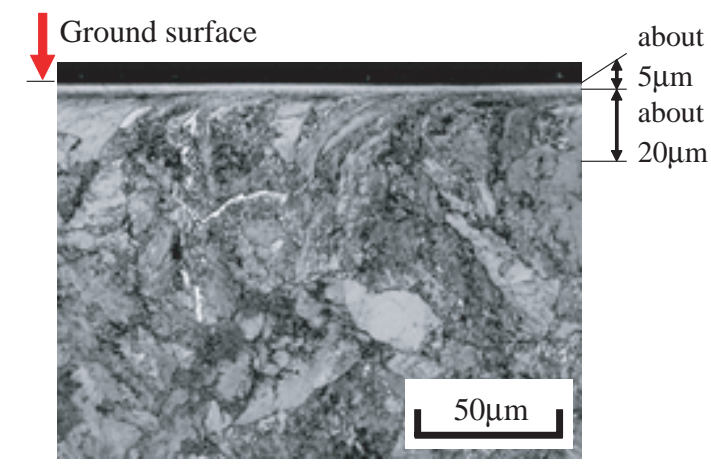

(b) Type D grinding stone

Fig. 10 Metallographic structure of the rail ated from friction during the grinding process. The thickness of the white etching layer was approximately $10 \mu \mathrm{m}$ with the current grinding stone while about $5 \mu \mathrm{m}$ with the type $\mathrm{D}$ grinding stone. A plastic flow layer could be observed under the white etching layer with a flow direction the same as the grinding direction. The thickness of the plastic flow layer was approximately 20 to $30 \mu \mathrm{m}$ for both test specimens.

If the abrasive grains in the grinding stone are not removed effectively during the grinding process, the cutting angle of the abrasive grain is blunted by the continuous friction on a one of its given planes with the surface of the rail specimen resulting decreasing the grinding performance and increasing frictional force. This frictional force generates heat which can cause a white etching layer. Following the process described above, the surface layer of a rail specimen would be covered with a thicker white etching layer if ground by low grinding-performance grinding stone.

\section{Conclusion}

A set of new grinding stones were developed in this study with a view to improving rail grinding efficiency. The prototype grinding stones were tested on a grinding test bench. The bench test conditions, namely rotation speed and pressing load, were determined after a series of preliminary tests based on that the assumption that the most favorable test conditions would be those which produced grinding chips similar in shape and size to those produced during field grinding operations.

Metallographic analyses of the rail specimens after grinding were then performed to investigate the influence of each of the prototype grinding stones. The results obtained in this study can be summarized as follows;

1. Seven grinding stones with different material and size of abrasive grain, different binding material and different hardness of grinding stone were prepared and provided for the bench tests. All the prototype grinding stones demonstrated a higher grinding performance than the current grinding stone.

2. Characterization of the rail specimens' tread surface showed that the influence of grinding on the rail material was more moderate with the prototype grinding stones than with the current grinding stone despite their higher grinding performance.

Based on these results, the developed grinding stone can be introduced to the field grinding operations as a substitute for the current grinding stone. A field test is now being arranged to evaluate the performance of the developed grinding stones in field grinding operational conditions, employing a grinding car equipped with the stones, first on rails in a yard then on rails in service.

\section{Acknowledgment}

The authors are grateful to the East Japan Railway Company for their help in the field investigations and to 
Noritake Bonded Abrasive Co., Ltd. for their assistance in this study and preparation of the prototype grinding stones.

\section{References}

[1] Shinichi TAKAGI and Tomomi TAKAYAMA, Rail Grinding for Tokaido Shinkansen, J. Japan Railway Civil Engineering Association, 2003 (4), pp.281-284 (in Japanese).
[2] Mitsunobu TAKIKAWA, Tsukasa ABE and Takayuki ONODERA, Analysis of Rolling Noise with Rail Grinding in Conventional Lines, Proceedings of the 61th Annual Conference of the Japan Society of Civil Engineers, 2006, pp.503-504 (in Japanese).

[3] Daisuke MINEGISHI, Review of Rail Grinding for Shinkansen, Shinsenro, 2005(8), pp.11-13 (in Japanese).

[4] Tomohiro YAMADA, Study of Effective Rail Grinding for Conventional Lines, Shinsenro, 2005(10), pp.19-21 (in Japanese). 